\title{
Statin Use and Its Association with Essential Tremor and Parkinson's Disease
}

\author{
Sherif Y. Shalaby ${ }^{\mathrm{a}}$ Elan D. Louis ${ }^{\mathrm{a}-\mathrm{c}}$ \\ ${ }^{\mathrm{a}}$ Department of Neurology, and ${ }^{\mathrm{b}}$ Center for Neuroepidemiology and Clinical Neurological Research, Yale School of \\ Medicine, and ' Department of Chronic Disease Epidemiology, Yale School of Public Health, Yale University, \\ New Haven, Conn., USA
}

\section{Key Words}

Essential tremor - Parkinson's disease - Tremor disorders .

Epidemiology $\cdot$ Statins

\begin{abstract}
Background: Statins have potent anti-inflammatory and immunomodulating effects, and may have neuroprotective properties in patients with Parkinson's disease (PD). There are no studies about the use of statins in the related tremor disorder, essential tremor (ET). We determined whether statin use differed in ET cases vs. controls and PD cases vs. controls. Methods: One hundred and thirty nine ET cases, 108 PD cases, and 124 controls participated in a research study of the epidemiology of movement disorders. They were frequency matched based on age and gender. Statin use was assessed by self-report. Results: In adjusted logistic regression analyses, statin use (current or ever) was inversely associated with PD (ORs 0.56-0.63), with marginal values ( $p$ values $=0.07-0.187$ ). In similar adjusted models, ET was not associated with statin use ( $p$ values $=0.45-0.50$ ). However, ET was inversely associated with longer-term statin use (adjusted OR 0.27, $\mathrm{p}$ values $=0.04-0.048$ ). Conclusions: We observed a marginally significant inverse association between PD and statin use. Although in primary analyses we
\end{abstract}

found no evidence that statin use was protective in $\mathrm{ET}$, there was an inverse association in analyses that assessed longer term use of statins. Further observational studies are warranted.

(c) 2016 S. Karger AG, Basel

\section{Introduction}

Statins have potent anti-inflammatory and immunomodulating effects, thereby leading to the hypothesis that these agents have neuroprotective properties $[1,2]$. A sizable number of studies have examined the association between statin use and odds or risk of Parkinson's disease (PD), and these have generated mixed results [3-6]. Thus, in a study in Denmark of 1,931 PD patients and 9,651 matched controls, there was an inverse association between PD diagnosis and short-term ( $\leq 1$ year) statin use. However, longer duration statin use was not associated with PD [3]. There was no association between PD and statin use in a case-control analysis using the United Kingdom-Based General Practice Research Database [6]. However, long-term statin use ( $\geq 5$ years) was inversely associated with PD in a sample of $312 \mathrm{PD}$ patients and 342 controls from 3 rural California counties [5]. Attempting

\section{KARGER}

E-Mail karger@karger.com

www.karger.com/ned
(C) 2016 S. Karger AG, Basel

0251-5350/16/0471-0011\$39.50/0
Elan D. Louis, MD, MS

Department of Neurology

Yale School of Medicine, Yale University

LCI 710, 15 York Street, PO Box 208018, New Haven, CT 06520-8018 (USA)

E-Mail elan.louis@yale.edu 
to summarize data from eleven studies, a recent metaanalysis concluded that statin use was associated with a reduced risk of $\mathrm{PD}$ (summary relative risk $=0.81,95 \% \mathrm{CI}$ 0.71-0.92) [7].

Essential tremor (ET) is a tremor disorder that shares a number of clinical and etiological features with PD [811]. Furthermore, in some postmortem studies, ET cases have a preponderance of Lewy bodies compared to agematched controls [12]. Hence, a number of studies have examined risk factors for PD among ET cases $[13,14]$. Yet to our knowledge, there have been no studies of the use of statins in ET. Our goal was to determine whether statin use differed in ET cases vs. normal controls. We also enrolled a group with $\mathrm{PD}$, comparing them to controls as well. These analyses capitalized on the enrollment of patients with ET and PD as well as controls in research study of the epidemiology of movement disorders [15].

\section{Methods}

\section{Participants and Evaluation}

ET cases, PD cases, and controls were enrolled in a study of the epidemiology of movement disorders at Columbia University Medical Center (CUMC; 2009-2014) [15]. All cases had received a diagnosis of ET or PD from their treating neurologist, one of the movement disorder neurologists at the Neurological Institute, CUMC. To facilitate enrollment, ET and PD cases were confined to those living in a geographical area within $2 \mathrm{~h}$ driving distance of CUMC [10]. One of the authors (E.D.L.) reviewed the office records of all selected ET and PD cases, and confirmed the diagnoses of PD using published diagnostic criteria [16]. ET cases also underwent a videotaped tremor examination and diagnostic confirmation as described further below.

Controls were recruited during the same time period as cases. These controls were identified using random digit telephone dialing within a defined set of telephone area codes represented by the cases within the New York Metropolitan area, and were selected from the same source population as the cases. During recruitment, controls were frequency-matched to ET cases based on age. The CUMC Internal Review Board approved all study procedures. Written informed consent was obtained upon enrollment.

During the in-person evaluation, conducted on all ET cases, PD cases and controls, the trained research worker administered clinical questionnaires (medical history and medications). This included a 10-15 min, 30-item, structured questionnaire that elicited data on history of statin use. This medication questionnaire was similar to the one used in an earlier study [17] investigating nonsteroidal anti-inflammatory medications among ET cases. The questionnaire initially asked, 'Do you currently take medications to lower your cholesterol?' and 'In the past did you ever take medications for cholesterol?' If they answered 'no' to both questions, the questionnaire was terminated. If they answered 'yes' to either question, we then further asked about the prescription of the common types of statin medication, duration of use, and current and highest dose ever prescribed in mg. Also, we categorized statins into lipophilic (e.g. atorvastatin, simvastatin, and pitavastatin) and hydrophilic (e.g. rosuvastatin, fluvastatin, and pravastatin), as lipophilic statins cross the blood brain barrier and demonstrate a neuroprotective role $[18,19]$. Furthermore, we investigated whether statin use for up to 12 years was associated with PD or ET; this was based on a published study demonstrating a neuroprotective role of statin use in this time frame [20].

Medical comorbidity was assessed using the Cumulative Illness Rating Scale (CIRS), in which the severity of medical problems ( 0 (none) -3 (severe)) was rated in 14 body systems (e.g. cardiac, respiratory) and a CIRS score was assigned (range 0-42 (maximal co-morbidity)) to each participant [21]. Years since the time of last hospitalization, a measure of medical comorbidity, was also assessed. Tobacco exposure was assessed, and cigarette smoking was calculated in pack years; participants who never smoked were assigned ' 0 ' for pack years. We also recorded whether the participant had a diagnosis of diabetes mellitus, which has been associated with statin use [22]. Furthermore, with the subject standing, measurements were taken of body weight to the nearest 0.1 pound using a balance scale designed for field surveys (ScaleTronix 5600, White Plains, N.Y., USA). Height was measured to the nearest $0.5 \mathrm{~cm}$ using a movable anthropometer (GPM Martin Type, Pfister Inc., Carlstadt, N.J., USA). Body mass index (BMI) was calculated as weight in $\mathrm{kg}$ divided by the square of height in meters.

All ET cases and controls also underwent a standardized videotaped tremor examination, which included tests of postural and kinetic tremors and assessments for the presence of other involuntary movements. The aim was to use the videotape to carefully validate ET diagnoses (and lack thereof in controls) using rigorous research-grade diagnostic criteria [23]. Thus, each videotape was reviewed by a senior neurologist specializing in movement disorders (E.D.L.) who confirmed the ET diagnoses using Washington Heights-Inwood Genetic Study of ET (WHIGET) diagnostic criteria (moderate or greater amplitude kinetic tremor (tremor rating $\geq 2$ ) during 3 or more tests or a head tremor, in the absence of PD, or another cause) [23]. The WHIGET tremor rating scale was also used to rate postural and kinetic tremor during each test: 0 (none), 1 (mild), 2 (moderate), 3 (severe). These ratings resulted in a total tremor score (range 0-36).

\section{Final Sample Selection}

To frequency match by age and gender across all 3 diagnostic groups, we excluded 82 (18.1\%) of 453 enrollees. This matching was performed by selecting a group of individuals in each of the 2 remaining diagnostic groups (PD, controls) whose age and gender conformed to the distribution observed in the ET cases. This matching was performed within each diagnostic category blinded to all data other than age and gender. The final sample included 371 enrollees: $139(100 \%)$ of 139 ET cases, 108 (80.6\%) of $134 \mathrm{PD}$ cases, and $124(68.9 \%)$ of 180 controls.

\section{Statistical Analyses}

Analyses were performed using the statistical software package SPSS (version 21.0; SPSS, Inc., Chicago, Ill., USA). We compared demographic and clinical characteristics across the 3 diagnostic groups (PD, ET, controls; table 1). When variables were not normally distributed (i.e. Kolmogorov-Smirnov test statistic $\mathrm{p}$ value $<0.05)$, non-parametric tests were used. When a difference was 
Table 1. Demographic data and comorbidities of 371 participants

\begin{tabular}{|c|c|c|c|c|}
\hline & PD & ET & Control & $\mathrm{p}$ value \\
\hline Numbers & 108 & 139 & 124 & \\
\hline Age, years & $71.3 \pm 6.4(71.0)$ & $71.9 \pm 12.8(73.0)$ & $71.5 \pm 9.1(72.0)$ & $0.12^{\mathrm{a}}$ \\
\hline Female gender & $60(55.6)$ & $73(52.5)$ & $67(54.0)$ & $0.89^{\mathrm{b}}$ \\
\hline Education, years & $16.3 \pm 2.8(16.0)$ & $16.1 \pm 2.6(16.0)$ & $16.2 \pm 2.7(16.0)$ & $0.61^{\mathrm{a}}$ \\
\hline Cigarette pack years & $9.3 \pm 17.8(0.0)$ & $11.4 \pm 18.9(1.0)$ & $10.6 \pm 16.1(2.0)$ & $0.21^{\mathrm{a}}$ \\
\hline $\mathrm{BMI}, \mathrm{kg} / \mathrm{m}^{2}$ & $24.9 \pm 5.7(24.3)$ & $25.3 \pm 5.1(25.0)$ & $26.0 \pm 7.0(25.6)$ & $0.35^{\mathrm{a}}$ \\
\hline Number of prescription medications & $5.8 \pm 2.8(5.0)^{*}$ & $4.9 \pm 3.2(4.0)^{*}$ & $3.5 \pm 2.9(3.0)$ & $<0.001^{\mathrm{a}}$ \\
\hline Years since last hospitalization & $11.5 \pm 16.0(4.0)$ & $11.5 \pm 16.4(4.0)$ & $12.4 \pm 14.6(7.0)$ & $0.44^{\mathrm{a}}$ \\
\hline CIRS score & $7.2 \pm 3.2(7.0)$ & $7.3 \pm 3.6(7.0)$ & $6.8 \pm 3.9(7.0)$ & $0.48^{\mathrm{a}}$ \\
\hline Diabetes mellitus & $9(8.4)$ & $11(8.1)$ & $14(11.4)$ & $0.62^{\mathrm{b}}$ \\
\hline Daily levodopa dosage, mg & $529.8 \pm 394.7$ & NA & NA & NA \\
\hline \multicolumn{5}{|c|}{$\begin{array}{l}\text { Values are mean } \pm \text { SD (median) or number (percentage). } \\
\text { a Kruskal-Wallis test comparing all } 3 \text { groups. } \\
{ }^{b} \text { Chi-square test comparing all } 3 \text { groups. } \\
\text { * Significantly different from controls }(\mathrm{p}<0.05 \text {, Mann-Whitney U test). } \\
\text { NA = Not applicable. }\end{array}$} \\
\hline
\end{tabular}

detected across the 3 groups, we further compared each diagnostic group to controls (i.e. ET vs. controls, PD vs. controls). All tests were 2 -sided, and significance was accepted at the $5 \%$ level. To assess the relationship of ET and PD to statin use we used logistic regression analyses. We first assessed whether statin use (current or ever) was associated with either ET or PD. Also, we categorized statins into lipophilic (e.g. atorvastatin, simvastatin, and pitavastatin) and hydrophilic (e.g. rosuvastatin, fluvastatin, and pravastatin), as lipophilic statins cross the blood brain barrier and demonstrate a neuroprotective role. We then assessed whether longterm statin use (i.e. for up to 12 years) was associated with ET or PD. We also used an alternative cut point for long-term statin use (i.e. for up to 10 years). In these logistic regression analyses, we began with an unadjusted model. Then, in adjusted models, we first considered variables that were associated with both the movement disorder and with statin use ('conservative model' (more restrictive criteria for confounding)) and then considered variables that were associated with either the movement disorder or with statin use ('liberal model' (less restrictive criteria for confounding)) at a $\mathrm{p}<0.05$ level. These analyses generated ORs with $95 \%$ CIs. Given the large number of comparisons in the secondary analysis of specific statin medications $(n=8$; table 2$)$, a significant $\mathrm{p}$ value for the secondary analysis was conservatively set at $<0.006$ (i.e. $0.05 / 8$ ); in this analysis, $\mathrm{p}$ values between 0.006 and 0.05 were viewed as marginally significant. In other analyses, a Mann-Whitney $U$ test was used to determine whether total tremor score in ET differed between categories of statin use (current or ever use - yes vs. no). Furthermore, we used a Spearman's correlation coefficient to assess the relationship between tremor severity (i.e. total tremor score) in ET and duration of statin use in years.

Study Power

Using published data on the use of statins in PD cases vs. controls (17\% of PD cases and $34 \%$ of controls used cholesterol lowering drugs) [4], we determined that a sample size of 103 per group

Statin Use and Its Association with ET and PD would provide us with $80 \%$ power (assuming alpha $=0.05$ ). Thus, our sample of 139 ET, 108 PD and 124 controls (mean = 124 per group) was adequately powered to detect case-control differences similar to those reported previously.

\section{Results}

The 3 groups were similar with respect to age, gender, education, cigarette pack years, BMI, and a variety of additional clinical features (table 1). The total number of prescription medications was significantly higher in PD and ET cases than controls (table 1).

The groups were similar with respect to the use (ever) of statins and with respect to the use (current) of statins (table 2). The duration of statin use was no different in ET and PD cases than controls. However, a significantly lower proportion of ET cases than controls had used statins for up to 12 years (chi-square test $=5.60, \mathrm{p}=0.018$ ) and for up to 10 years (chi-square test $=7.34 ; \mathrm{p}=0.007$; table 2). When comparing the 3 groups with respect to the proportion that used each type of statin, there were no group differences (table 2).

Using our control sample, we compared statin users vs. non statin users (table 3 ). Statin users are older, more likely to be male, had more cigarette pack years, took more prescription medications, had higher CIRS scores, and were marginally more likely to have diabetes mellitus (table 3). 
Table 2. Statin use and dosage among 371 participants

\begin{tabular}{|c|c|c|c|c|}
\hline & $\mathrm{PD}$ & ET & Control & $\mathrm{p}$ value \\
\hline Numbers & 108 & 139 & 124 & \\
\hline Ever (past or current) statin use & $54(50.0)$ & $74(53.2)$ & $59(47.6)$ & $0.65^{\mathrm{b}}$ \\
\hline Ever (past or current) hydrophilic statin use & $9(8.3)$ & $16(11.5)$ & $12(9.7)$ & $0.70^{\mathrm{b}}$ \\
\hline Ever (past or current) lipophilic statin use & $42(38.9)$ & $50(36.0)$ & $45(36.3)$ & $0.88^{\mathrm{b}}$ \\
\hline Current statin use & $49(45.4)$ & $71(51.1)$ & $52(41.9)$ & $0.32^{\mathrm{b}}$ \\
\hline Duration (years) of statin use & $5.8 \pm 5.4(5.0)$ & $6.5 \pm 7.1(5.0)$ & $4.8 \pm 4.6(3.5)$ & $0.71^{\mathrm{a}}$ \\
\hline Statin use for up to 10 years & $100(92.6)$ & $120(86.3)^{*}$ & $119(96.0)$ & $0.02^{\mathrm{b}}$ \\
\hline Statin use for up to 12 years & $101(93.5)$ & $124(89.2)^{*}$ & $120(96.8)$ & $0.05^{\mathrm{b}}$ \\
\hline \multicolumn{5}{|l|}{ Simvastatin use } \\
\hline Yes & $20(18.5)$ & $21(15.1)$ & $24(19.4)$ & $0.63^{\mathrm{b}}$ \\
\hline Current dose & $24.5 \pm 16.7(20.0)$ & $28.8 \pm 15.7(20.0)$ & $27.0 \pm 11.1(20.0)$ & $0.37^{\mathrm{a}}$ \\
\hline Highest dose & $26.0 \pm 16.7(20.0)$ & $29.3 \pm 15.2(20.0)$ & $30.4 \pm 18.7(20.0)$ & $0.53^{\mathrm{a}}$ \\
\hline \multicolumn{5}{|l|}{ Atorvastatin use } \\
\hline Yes & $21(19.4)$ & $27(19.4)$ & $21(16.9)$ & $0.84^{\mathrm{b}}$ \\
\hline Current dose & $26.0 \pm 22.3(15.0)$ & $20.8 \pm 16.2(20.0)$ & $20.0 \pm 19.4(10.0)$ & $0.42^{\mathrm{a}}$ \\
\hline Highest dose & $28.0 \pm 25.3(15.0)$ & $22.3 \pm 19.6(20.0)$ & $19.1 \pm 19.1(10.0)$ & $0.38^{\mathrm{a}}$ \\
\hline \multicolumn{5}{|l|}{ Rosuvastatin use } \\
\hline Yes & $4(3.7)$ & $9(6.5)$ & $8(6.5)$ & $0.74^{\mathrm{b}}$ \\
\hline Current dose & $20.3 \pm 19.5(20.0)$ & $12.2 \pm 4.4(10.0)$ & $16.3 \pm 11.6(10.0)$ & $0.78^{a}$ \\
\hline Highest dose & $27.0 \pm 22.5(40.0)$ & $13.3 \pm 5.0(10.0)$ & $17.9 \pm 11.5(10.0)$ & $0.57^{\mathrm{a}}$ \\
\hline \multicolumn{5}{|l|}{ Pravastatin use } \\
\hline Yes & $5(4.6)$ & $7(5.0)$ & $4(3.2)$ & $0.76^{\mathrm{b}}$ \\
\hline Current dose & $55.0 \pm 30.0(40.0)$ & $37.1 \pm 7.6(40.0)$ & $45.0 \pm 25.2(40.0)$ & $0.47^{\mathrm{a}}$ \\
\hline Highest dose & $65.0 \pm 30.0(60.0)$ & $37.1 \pm 7.6(40.0)$ & $45.0 \pm 25.2(40.0)$ & $0.19^{\mathrm{a}}$ \\
\hline \multicolumn{5}{|l|}{ Lovastatin use } \\
\hline Yes & $3(5.4)$ & $2(2.2)$ & $1(1.4)$ & $0.37^{\mathrm{b}}$ \\
\hline Current dose & $25.0 \pm 7.1(25.0)$ & $46.7 \pm 30.6(40.0)$ & $10.0 \pm 0.0(10.0)$ & $0.25^{\mathrm{a}}$ \\
\hline Highest dose & $25.0 \pm 7.1(25.0)$ & $46.7 \pm 30.6(40.0)$ & $10.0 \pm 0.0(10.0)$ & $0.25^{\mathrm{a}}$ \\
\hline \multicolumn{5}{|l|}{ Pitavastatin use } \\
\hline Yes & $1(0.9)$ & $2(1.4)$ & $1(0.8)$ & $0.87^{\mathrm{b}}$ \\
\hline Current dose & $1.0 \pm 0.0(1.0)$ & $2.0 \pm 0.0(2.0)$ & $2.0 \pm 0.0(2.0)$ & $0.37^{\mathrm{a}}$ \\
\hline Highest dose & $1.0 \pm 0.0(1.0)$ & $2.0 \pm 0.0(2.0)$ & $2.0 \pm 0.0(2.0)$ & $0.37^{\mathrm{a}}$ \\
\hline \multicolumn{5}{|l|}{ Ezetimibe use } \\
\hline Yes & $0(0.0)$ & $6(4.3)$ & $1(0.8)$ & $0.03^{\mathrm{b}}$ \\
\hline Current dose & NA & $10.0 \pm 0.0(10.0)$ & $10.0 \pm 0.0(10.0)$ & $0.99^{\mathrm{a}}$ \\
\hline Highest dose & NA & $10.0 \pm 0.0(10.0)$ & $10.0 \pm 0.0(10.0)$ & $0.99^{\mathrm{a}}$ \\
\hline \multicolumn{5}{|l|}{ Fluvastatin use } \\
\hline Yes & $0(0.0)$ & $0(0.0)$ & $0(0.0)$ & \\
\hline Current dose & NA & NA & NA & \\
\hline Highest dose & NA & NA & NA & NA \\
\hline \multicolumn{5}{|l|}{ Other statin use } \\
\hline Yes & $0(0.0)$ & $3(3.3)$ & $2(2.8)$ & $0.40^{\mathrm{b}}$ \\
\hline Current dose & NA & $505.0 \pm 646.3(145.0)$ & $145 \pm 0.0(145.0)$ & $0.99^{\mathrm{a}}$ \\
\hline Highest dose & NA & $505.0 \pm 646.3(145.0)$ & $145 \pm 0.0(145.0)$ & $0.99^{\mathrm{a}}$ \\
\hline $\begin{array}{l}\text { Values are mean } \pm \text { SD (median) or num } \\
\text { a Kruskal-Wallis test comparing all } 3 \text { gr } \\
{ }^{b} \text { Chi-square test comparing all } 3 \text { groups } \\
{ }^{*} \text { Significantly different from controls ( } \mathrm{p}\end{array}$ & $\begin{array}{l}\text { rcentage). } \\
\text {, chi-square test). }\end{array}$ & & & \\
\hline
\end{tabular}

In an unadjusted logistic regression analysis, statin use (current or ever) was not associated with either PD or ET (table 4). In adjusted logistic regression analyses, statin use (current or ever) was inversely associated with PD (OR 0.56 (conservative model) and OR 0.63 (liberal model)), with marginal values ( $\mathrm{p}$ values $=0.07-0.18$; table 4). In adjusted models, ET was not associated with statin use ( $\mathrm{p}$ values $=0.45-0.50$; table 4 ). However, ET was inversely associated with statin use for up to 12 years (OR 0.28 (unadjusted model), OR 0.27 (conservative 
Table 3. Characteristics of statin users vs. non users among controls

\begin{tabular}{lccc}
\hline & Statin users & Not statin users & p value \\
\hline Numbers & 59 & 65 & \\
Age, years & $73.7 \pm 8.3(73.0)$ & $69.5 \pm 9.5(71.0)$ & $0.003^{\mathrm{a}}$ \\
Female gender & $25(42.3)$ & $42(64.6)$ & $0.01^{\mathrm{b}}$ \\
Education, years & $16.4 \pm 2.5(16.0)$ & $16.0 \pm 2.9(16.0)$ & $0.40^{\mathrm{a}}$ \\
Cigarette pack years & $11.9 \pm 13.9(8.0)$ & $9.4 \pm 17.7(0.0)$ & $0.02^{\mathrm{a}}$ \\
BMI, kg/m & $26.2 \pm 5.0(26.0)$ & $25.9 \pm 8.3(24.1)$ & $0.32^{\mathrm{a}}$ \\
Number of prescription medications & $4.8 \pm 2.9(4.5)$ & $2.3 \pm 2.4(1.0)$ & $<0.0001^{\mathrm{a}}$ \\
Years since last hospitalization & $11.4 \pm 13.4(7.0)$ & $13.4 \pm 15.7(7.0)$ & $0.49^{\mathrm{a}}$ \\
CIRS score & $7.8 \pm 4.0(7.0)$ & $5.9 \pm 3.6(6.0)$ & $0.007^{\mathrm{a}}$ \\
Diabetes mellitus & $10(17.0)$ & $4(6.1)$ & $0.06^{\mathrm{b}}$ \\
\hline
\end{tabular}

Values are mean \pm SD (median) or number (percentage).

${ }^{a}$ Mann-Whitney U test comparing 2 groups.

${ }^{\mathrm{b}}$ Chi-square test comparing 2 groups.

Table 4. Logistic regression analysis of statin use in PD and ET

\begin{tabular}{|c|c|c|c|c|c|c|c|c|c|}
\hline Diagnosis & \multicolumn{3}{|c|}{ Unadjusted model } & \multicolumn{3}{|c|}{ Liberal adjusted model $^{1}$} & \multicolumn{3}{|c|}{ Conservative adjusted model ${ }^{2}$} \\
\hline $\mathrm{PD}$ & 1.10 & $0.66-1.85$ & 0.71 & 0.63 & $0.32-1.23$ & 0.18 & 0.56 & $0.30-1.04$ & 0.07 \\
\hline ET & 1.25 & $0.77-2.04$ & 0.36 & 0.81 & $0.44-1.50$ & 0.50 & 0.80 & $0.45-1.42$ & 0.45 \\
\hline Controls & 1.00 & & & 1.00 & & & 1.00 & & \\
\hline $\mathrm{PD}$ & 1.11 & $0.66-1.90$ & 0.68 & 0.82 & $0.42-1.58$ & 0.54 & 0.65 & $0.35-1.19$ & 0.16 \\
\hline ET & 0.99 & $0.60-1.63$ & 0.96 & 0.75 & $0.41-1.35$ & 0.33 & 0.69 & $0.39-1.21$ & 0.20 \\
\hline Controls & 1.00 & & & 1.00 & & & 1.00 & & \\
\hline \multicolumn{10}{|c|}{ Statin use (current or ever) (hydrophilic) } \\
\hline $\mathrm{PD}$ & 0.85 & $0.34-2.10$ & 0.72 & 0.34 & $0.11-1.05$ & 0.06 & 0.51 & $0.18-1.43$ & 0.20 \\
\hline ET & 1.21 & $0.55-2.68$ & 0.63 & 0.85 & $0.35-2.02$ & 0.71 & 0.94 & $0.40-2.21$ & 0.89 \\
\hline \multicolumn{10}{|c|}{ Statin use for up to 12 years } \\
\hline ET & 0.28 & $0.09-0.85$ & 0.03 & 0.27 & $0.07-0.99$ & 0.048 & 0.27 & $0.07-0.97$ & 0.04 \\
\hline Controls & 1.00 & & & 1.00 & & & 1.00 & & \\
\hline \multicolumn{10}{|c|}{ Statin use for up to 10 years } \\
\hline $\mathrm{PD}$ & 0.53 & $0.17-1.67$ & 0.27 & 0.83 & $0.20-3.46$ & 0.80 & 0.79 & $0.22-2.91$ & 0.73 \\
\hline ET & 0.27 & $0.10-0.73$ & 0.01 & 0.26 & $0.08-0.82$ & 0.02 & 0.27 & $0.09-0.86$ & 0.02 \\
\hline Controls & 1.00 & & & 1.00 & & & 1.00 & & \\
\hline
\end{tabular}

${ }^{1}$ Adjusted for number of prescription medications, age in years, gender, pack years (cigarettes), and CIRS.

2 Adjusted for number of prescription medications.

model) and OR 0.27 (liberal model), $\mathrm{p}$ values $=0.03-$ 0.048 ; table 4). Using an alternative cut point for longterm statin use (i.e. for up to 10 years), it was found that the association with ET was even more robust (OR 0.27 (unadjusted model), OR 0.27 (conservative model) and
OR 0.26 (liberal model), p values $=0.01-0.02$; table 4 ). By contrast, PD was not associated with such long-term statin use.

Tremor severity (i.e. total tremor score) was not associated with the category of statin use (yes vs. no (cur- 
rent or ever use; $\mathrm{p}=0.83$, Mann-Whitney $\mathrm{U}$ test)). Furthermore, total tremor score in ET did not correlate with the duration of statin use (Spearman's $\mathrm{r}=-0.04 ; \mathrm{p}=$ $0.64)$.

\section{Discussion}

We investigated whether ET or PD was associated with statin use. In an adjusted model, PD was inversely associated with statin use (current or ever, OR 0.56), but with marginal statistical significance $(\mathrm{p}=0.07)$. This inverse association between PD and statin use has been previously observed in larger studies [5,7]. ET was not associated with statin use (current or ever); however, there was an inverse association in an analysis that assessed longerterm use of statins.

ET is a chronic, progressive neurological disease; it may even be a family of diseases. The biological mechanisms that underlie ET are not entirely clear although there is considerable evidence to support neurodegenerative mechanisms [24-26]. Whether the specific mechanisms involve oxidative stress or neuroinflammation is not known, although it was with this possibility in mind that we chose to examine the association between statin use and ET. Statins may reduce oxidative stress and neuroinflammation. Their links with $\mathrm{PD}$, along with the links between $\mathrm{PD}$ and ET, provided a rationale to study their use in ET in these analyses [11,27]. In our primary analyses, we did not find evidence of an association between ET and statin use; however, in an analysis that assessed longer-term use, there was an inverse association. In a prior study of $156 \mathrm{ET}$ cases and 220 controls, we conducted detailed dietary assessments and tested the hypothesis that diminished use of nutritional antioxidants was associated with ET. In that study, there was no evidence that current nutritional antioxidant exposure differed in ET cases and controls [28]. Further studies are warranted.
This study should be interpreted within the context of several limitations. First, this was a case-control study rather than a cohort study. This precludes direct inferences about causality in the relationship between statin use and neurological diseases. Second, we assessed the use of statins by self-report rather than pharmacy records, raising potential questions about the validity of the primary data. The confirmation of a prior finding of an inverse association between PD and statin use, however, suggests that the self-report data are to some extent valid. Finally, the study was powered to detect a doubling in the proportion of statin users across diagnostic groups; more subtle group differences might not have been detected. Strengths of the study include the novelty of the question we pose (i.e. the association between statin use and other movement disorders aside from PD), the enrollment of nearly 400 participants, the fact that cases had all received a diagnosis of ET or PD that was carefully assigned by a movement disorder neurologist (thereby lowering the risk of disease misclassification), the inclusion of a disease group (PD) with a well-known inverse association with statin use (i.e. enrollment of an internal control), the careful frequency matching of our 3 diagnostic groups by age and gender, the fact that controls were carefully selected from the same source population as the cases, and the ability to assess and adjust for the effects of numerous potential confounding variables.

We observed a marginally significant inverse association between PD and statin use. Although in primary analyses we found no evidence that statin use was protective in ET, there was an inverse association in an analysis that assessed longer-term use of statins. Further observational studies are warranted.

\section{Acknowledgments and Funding}

All authors have no conflicts of interest. This study is supported by NIH (R01 NS039422 and R01 NS094607).

\section{References}

1 Becker C, Meier CR: Statins and the risk of Parkinson disease: an update on the controversy. Expert Opin Drug Saf 2009;8:261-271.

2 Wood WG, Eckert GP, Igbavboa U, Muller WE: Statins and neuroprotection: a prescription to move the field forward. Ann N Y Acad Sci 2010;1199:69-76.

3 Ritz B, Manthripragada AD, Qian L, Schernhammer E, Wermuth L, Olsen J, Friis S: Statin use and Parkinson's disease in Denmark. Mov Disord 2010;25:1210-1216.

4 Huang X, Chen H, Miller WC, Mailman RB, Woodard JL, Chen PC, Xiang D, Murrow RW, Wang YZ, Poole C: Lower low-density lipoprotein cholesterol levels are associated with Parkinson's disease. Mov Disord 2007;22:377-381.

5 Wahner AD, Bronstein JM, Bordelon YM, Ritz B: Statin use and the risk of Parkinson disease. Neurology 2008;70(16 pt 2):14181422.

6 Becker C, Jick SS, Meier CR: Use of statins and the risk of Parkinson's disease: a retrospective case-control study in the UK. Drug Saf 2008; 31:399-407.

7 Bai S, Song Y, Huang X, Peng L, Jia J, Liu Y, Lu H: Statin use and the risk of Parkinson's disease: an updated meta-analysis. PLoS One 2016;11:e0152564.
16

Neuroepidemiology 2016;47:11-17 DOI: $10.1159 / 000446655$
Shalaby/Louis 
8 LaRoia H, Louis ED: Association between essential tremor and other neurodegenerative diseases: what is the epidemiological evidence? Neuroepidemiology 2011;37:1-10.

9 Vilarino-Guell C, Wider C, Ross OA, Jasinska-Myga B, Kachergus J, Cobb SA, Soto-Ortolaza AI, Behrouz B, Heckman MG, Diehl NN, Testa CM, Wszolek ZK, Uitti RJ, Jankovic J, Louis ED, Clark LN, Rajput A, Farrer MJ: Lingol and lingo 2 variants are associated with essential tremor and Parkinson disease. Neurogenetics 2010;11:401-408.

10 Louis ED, Ottman R: Is there a one-way street from essential tremor to Parkinson's disease? Possible biological ramifications. Eur J Neurol 2013;20:1440-1444

11 Thenganatt MA, Jankovic J: The relationship between essential tremor and Parkinson's disease. Parkinsonism Relat Disord 2016; 22(suppl 1):S162-S165.

12 Louis ED, Faust PL, Vonsattel JP, Honig LS, Rajput A, Robinson CA, Rajput A, Pahwa R, Lyons KE, Ross GW, Borden S, Moskowitz $\mathrm{CB}$, Lawton A, Hernandez N: Neuropathological changes in essential tremor: 33 cases compared with 21 controls. Brain 2007;130(pt 12):3297-3307.

13 Garcia-Martin E, Martinez C, Alonso-Navarro $\mathrm{H}$, Benito-Leon J, Lorenzo-Betancor $\mathrm{O}$, Pastor P, Lopez-Alburquerque T, Samaranch L, Lorenzo E, Agundez JA, Jimenez-Jimenez FJ: H1-mapt and the risk for familial essential tremor. PLoS One 2012;7:e41581.
14 Louis ED, Benito-Leon J, Bermejo-Pareja F; Neurological Disorders in Central Spain (NEDICES) Study Group: Population-based prospective study of cigarette smoking and risk of incident essential tremor. Neurology 2008;70:1682-1687.

15 Louis ED, Rao AK: Functional aspects of gait in essential tremor: a comparison with agematched Parkinson's disease cases, dystonia cases, and controls. Tremor Other Hyperkinet Mov (N Y) 2015;5:pii:tre-5-308.

16 Hughes AJ, Ben-Shlomo Y, Daniel SE, Lees AJ: What features improve the accuracy of clinical diagnosis in Parkinson's disease: a clinicopathologic study. Neurology 1992;42: 1142-1146.

17 Pan J, Michalec M, Louis ED: Non-steroidal anti-inflammatory drug use and essential tremor. Neuroepidemiology 2014;43:145-149.

18 Sierra S, Ramos MC, Molina P, Esteo C, Vazquez JA, Burgos JS: Statins as neuroprotectants: a comparative in vitro study of lipophilicity, blood-brain-barrier penetration, lowering of brain cholesterol, and decrease of neuron cell death. J Alzheimers Dis 2011;23:307-318.

19 Kim MC, Ahn Y, Jang SY, Cho KH, Hwang SH, Lee MG, Ko JS, Park KH, Sim DS, Yoon NS, Yoon HJ, Kim KH, Hong YJ, Park HW, Kim JH, Jeong MH, Cho JG, Park JC, Kang JC: Comparison of clinical outcomes of hydrophilic and lipophilic statins in patients with acute myocardial infarction. Korean J Intern Med 2011;26:294-303.

20 Gao X, Simon KC, Schwarzschild MA, Ascherio A: Prospective study of statin use and risk of Parkinson disease. Arch Neurol 2012;69: 380-384.
21 Linn BS, Linn MW, Gurel L: Cumulative illness rating scale. J Am Geriatr Soc 1968;16: 622-626.

22 Redberg RF, Katz MH: Reassessing benefits and risks of statins. N Engl J Med 2012;367: 776; author reply 776 .

23 Louis ED, Ottman R, Ford B, Pullman S, Martinez M, Fahn S, Hauser WA: The Washington heights-inwood genetic study of essential tremor: methodologic issues in essentialtremor research. Neuroepidemiology 1997; 16:124-133.

24 Benito-Leon J: Essential tremor: a neurodegenerative disease? Tremor Other Hyperkinet Mov 2014;4:252.

25 Bonuccelli U: Essential tremor is a neurodegenerative disease. J Neural Transm (Vienna) 2012;119:1383-1387; discussion 1373.

26 Louis ED: Re-thinking the biology of essential tremor: from models to morphology. Parkinsonism Relat Disord 2014;20(suppl 1):S88S93.

27 Benito-Leon J, Louis ED, Bermejo-Pareja F; Neurological Disorders in Central Spain Study Group: Risk of incident Parkinson's disease and parkinsonism in essential tremor: a population based study. J Neurol Neurosurg Psychiatry 2009;80:423-425.

28 Louis ED, Jurewicz EC, Parides MK: Casecontrol study of nutritional antioxidant intake in essential tremor. Neuroepidemiology 2005;24:203-208. 